\title{
Perfil das vítimas de acidente motociclístico atendidas pelo serviço de atendimento móvel de urgência
}

\author{
Profile of victims of motorcycle accident attended by the mobile customer service urgency \\ service
}

Perfil de las víctimas de accidente de motocicleta que asistieron a la urgencia de los clientes de servicios móviles

Maria do Socorro de Sousa Abreu', Tatiana Naiana Rodrigues dos Santos Porto', Maria Tamires Alves Ferreira', Nisleide Vanessa Pereira das Neves ${ }^{1}$, Luciana Stanford Baldoino ${ }^{1 *}$, Vinícius de Sousa Martins ${ }^{1}$, Dorivaldo Pereira Carvalho' ${ }^{1}$, Sônia Maria Leite Alcântara'.

\section{RESUMO}

Objetivo: Analisar o perfil das vítimas de acidente motociclístico atendidas pelo Suporte Avançado do Serviço de Atendimento Móvel de Urgência de Timon (MA) no ano de 2016. Métodos: Estudo quantitativo e descritivo. Foram analisadas 100 fichas de atendimentos realizados para motociclistas no ano de 2016, pela Unidade de Suporte Avançado do Serviço de Atendimento Móvel de Urgência. Resultados: Os acidentes com motocicleta foram mais predominantes no sexo masculino (69\%), na faixa etária entre 21 e 30 anos (23\%), vítimas jovens em idade considerada economicamente ativa. Nos fins de semana aconteceu maior número de acidentes, principalmente aos sábados (34\%). Das lesões encontradas, prevalecem às escoriações (65\%) e o local mais afetado foram os membros inferiores (38\%), seguido da cabeça (29\%), o que revela a importância do uso de capacete. Conclusão: Verifica-se a importância em realizar uma sensibilização dos profissionais que prestam atendimento no serviço móvel para o preenchimento da ficha de atendimento bem como realizar medidas educativas e preventivas de conscientização para um trânsito mais seguro.

Palavras-chave: Acidentes de Trânsito, Enfermagem, Assistência de Enfermagem.

\begin{abstract}
Objective: To analyze the profile of motorcycle accident victims assisted by the Advanced Support of Timon Mobile Emergency Care Service (MA) in 2016. Methods: Quantitative and descriptive study. We analyzed 100 records of attendances made to motorcyclists in 2016 by the Advanced Support Unit of the Mobile Emergency Care Service Results: Motorcycle accidents were more frequent among males (69\%), aged between 21 and 30 years (23\%), young victims of economically active age. On weekends there was a greater number of accidents, especially on Saturdays (34\%). Of the lesions found, abrasions prevail $(65 \%)$ and the most affected site were the lower limbs (38\%), followed by the head $(29 \%)$, which reveals the importance of helmet use. Conclusion: It is important to raise awareness among professionals who provide care in mobile service to fill out the form and perform educational and preventive awareness measures for safer traffic.
\end{abstract}

Key words: Traffic Accidents, Nursing, Nursing Care.

\section{RESUMEN}

Objetivo: analizar el perfil de las víctimas de accidentes de motocicleta a las que asistió el Servicio avanzado de atención móvil de emergencia (MA) de Timon en 2016. Métodos: estudio cuantitativo y descriptivo. Analizamos 100 registros de asistencias hechas a motociclistas en 2016 por la Unidad de Soporte Avanzado del Servicio Móvil de Atención de Emergencia. Resultados: los accidentes de motocicleta fueron más frecuentes en hombres (69\%), con edades comprendidas entre 21 y 30 años (23\%), víctimas jóvenes de edad

1 Faculdade de Ensino Superior Múltiplo - IESM, Timon - MA. *E-mail: isbaldoino@hotmail.com 
económicamente activa. Los fines de semana hubo un mayor número de accidentes, especialmente los sábados (34\%). De las lesiones encontradas, prevalecen las abrasiones (65\%) y el sitio más afectado fueron las extremidades inferiores (38\%), seguidas de la cabeza (29\%), lo que revela la importancia del uso del casco. Conclusión: es importante crear conciencia entre los profesionales que brindan atención en el servicio móvil para completar el formulario y realizar medidas educativas y preventivas para un tráfico más seguro.

Palabras clave: Accidentes de Tránsito, Enfermería, Atención de Enfermería.

\section{INTRODUÇÃO}

No contexto atual da saúde no Brasil está ocorrendo uma mudança nos padrões de morbimortalidade inclusive a nível nacional, com expressivo número de acidentes de trânsito. Fatores como a ingestão de álcool, desobediência a sinalização, desrespeito a velocidade permitida e falta de atenção, são fatores que contribuem para o aumento dos índices de acidentes de trânsito, repercutindo assim, diretamente nos demais indicadores sociais do país de tal forma que, a cada ano, cerca de 50 mil pessoas morrem em acidentes de trânsito (BRASIL, 2017).

O Brasil está entre os países que lideram a lista de mortalidade por acidentes de trânsito e a maioria das mortes e internações por esse agravo é observada no sexo masculino, na raça negra, adultos jovens, em indivíduos com baixa escolaridade e principalmente motociclistas. Os Estados do Nordeste mostraram um aumento das taxas de mortalidade em acidentes de trânsito, bem como maiores proporções de ocorrência de acidente envolvendo bicicletas e motocicletas (ALMEIDA PMV, et al., 2016).

Ao analisar mais especificamente os acidentes motociclísticos, os dados são alarmantes, de acordo com o Sistema de Informações sobre Mortalidade do Ministério da Saúde (SIM), o Brasil registrou 4.292 mortes por acidente de motocicleta em 2003, número $280 \%$ menor do que o registrado 10 anos depois (12.040). Parte do aumento de acidentes envolvendo motos se deve ao crescimento vertiginoso da frota no país, entre 2003 e 2013, o número de motocicletas aumentou $247,1 \%$, enquanto a população teve um crescimento de 11\% (HANAUER MC, et al., 2018).

O Serviço de Atendimento Móvel de Urgência é o (principal componente móvel da rede de atenção às urgências. Com esse serviço, o Governo Federal visa diminuir o número de mortes, as sequelas causadas pela demora do atendimento e o tempo de internação. Dessa forma, o principal objetivo deste componente é receber e atender aos pedidos de ajuda médica de cidadãos acometidos por agravos agudos a sua saúde, de natureza clínica, e principalmente traumática, como nos casos de acidentes de trânsito (ALMEIDA GCM, et al., 2016).

Há muitos anos, a Organização das Nações Unidas (ONU) entende os acidentes de trânsito como um problema de saúde pública mundial, em razão de serem acompanhados por elevado índice de mortalidade cerca de 1,2 milhões de mortes por ano. Dessas mortes, 90\% ocorrem em países em desenvolvimento (MENDONÇA MFS, et al., 2017).

De 2008 a 2013, o número de internações devido a acidentes de transporte terrestre aumentou 72,4\%. Já em 2013, o Sistema Único de Saúde (SUS) registrou 170.805 internações por acidentes de trânsito e um gasto de 231 milhões de reais no atendimento às vítimas. Desse total de internações, 88.682 foi decorrente de motos, o que gerou custos ao SUS de 114 milhões de reais - crescimento de 170,8\% em relação a 2008. Os valores dos custos com as internações servem de alerta para toda a sociedade economicamente ativa por causa do ônus causado pelos acidentes envolvendo motociclistas. Apesar de elevados, estes valores não incluem gastos com reabilitação, medicação e o impacto em outras áreas da saúde, esses dados podem ser utilizados em subsídios para a melhhoria do planejamento de políticas de prevenção a acidentes envolvendo motociclistas (BRASIL, 2016).

Devido à violência por acidentes no trânsito apresentarem diversidades de agravos e necessitarem de ações específicas de prevenção, as considerações levantadas a respeito das intervenções realizadas na fase de atendimento no Atendimento Pré-Hospitalar (APH) de vítimas de acidentes de motocicleta é de suma 
importância ao fornecer informações que contribuem para a identificação de grupos mais vulneráveis e fatores de risco que podem auxiliar na elaboração de medidas preventivas (LEFUNDES DAA, et al., 2016).

O tempo entre o recebimento do chamado até o início dos primeiros socorros, a estabilização do paciente no local da cena e a chegada ao hospital são fatores importantes, oportunizando uma maior possibilidade de sobrevida. Assim, percebe- se a importância da existência das equipes de Atendimento Pré-Hospitalar (APH) bem qualificadas e que estejam preparadas para o cuidado de urgência às vítimas de trauma nas vias e lugares públicos. É pertinente salientar que o profissional deve ser capaz de realizar uma detalhada avaliação da gravidade do trauma, buscando reduzir ao máximo as complicações (DANTAS RAN, et al., 2018).

Dessa forma, realizou-se este estudo que reflete as causas e circunstâncias dos acidentes de motocicleta, uma vez que é essencial para a criação de estratégias de promoção de saúde e de prevenção para enfrentamento desse agravo. A pesquisa também se torna relevante, uma vez que poderá subsidiar pesquisas futuras sobre a temática e gerar informações que poderão contribuir para o aprimoramento de políticas públicas mais efetivas no tocante às ações de prevenção, educação, proteção e recuperação da saúde e reabilitação dos indivíduos envolvidos em acidentes motociclísticos. Diante disso, o objetivo deste estudo é analisar o perfil de vida das vítimas de acidente motociclístico atendidas pelo Suporte Avançado do Serviço de Atendimento Móvel de Urgência de Timon (MA) no ano de 2016.

\section{MÉTODOS}

Trata-se de um estudo retrospectivo com abordagem quantitativa e descritiva, baseada em análise documental com informações coletadas no (SAMU) de Timon (MA). A população do estudo foi constituída por fichas de atendimento do SAMU pelas Unidades de Suporte Avançado de Vida às vítimas politraumatizadas, ou seja, com lesões múltiplas de diversas naturezas que podem afetar e/ou comprometer vários orgãos e sistemas, que sofreram acidentes motociclísticos no ano de 2016. Foram excluídas as fichas de atendimento de pacientes com diagnóstico de politrauma que não foram vítimas de acidentes motociclísticos ou que tiveram remoção antecipada.

Para a coleta de informações, durante o mês de novembro de 2017, foi realizada consulta manual das fichas de atendimento no ano de 2016 e selecionadas aquelas que se adequaram aos critérios de inclusão, totalizando 100 fichas, cujas informações foram transcritas para um formulário estruturado de coleta de dados elaborado pelos pesquisadores com base nas informações contidas nas fichas de registro de atendimento do SAMU.

As variáveis estudadas foram: idade, sexo e variáveis relacionadas ao tipo de ocorrência (dia da semana, horário, sinais de avaliação da gravidade, tipo de trauma, regiões corpóreas afetadas, uso de capacete, indícios de ingestão de bebida alcoólica e nível de consciência da vítima).

Os dados obtidos foram codificados para elaboração de um dicionário de dados em planilha do programa Microsoft Excel ${ }^{\circledR}$. Depois de transcritos, com o processo de dupla digitação que permite a correção de erros, foram elaborados gráficos e tabelas utilizados para discussão dos resultados. Procedeu-se à análise dos dados por meio de estatísticas descritivas simples.

A pesquisa foi registrada em um Comitê de Ética e Pesquisa (CEP) da Plataforma Brasil e submetida à apreciação pela direção do Serviço Avançado Móvel de Urgência (SAMU) de Timon (MA). A coleta de dados foi iniciada somente após aprovação da instituição e do CEP sob o parecer de no 2.401 .227 e CAAE 73875317.7.0000.8007.

Diante disso, o estudo atende a todos os procedimentos éticos, seguindo às recomendações da Resolução no 466/12 do Conselho Nacional de Saúde. Como a pesquisa foi realizada utilizando dados de atendimento prévios, era inviável a localização de cada um dos participantes que fazem parte da investigação. Dessa forma, não foi usado o Termo de Consentimento Livre e Esclarecido (TCLE), mas os pesquisadores assinaram um termo de compromisso assegurando a manutenção do anonimato e sigilo das informações acessadas e autorização do responsável da instituição para uso de banco de dados secundários. 


\section{RESULTADOS}

Foram analisadas 100 fichas de atendimento a vítimas de acidentes motociclísticos atendidas pela unidade avançada do SAMU, destas 69 (69\%) eram do sexo masculino, a idade variou de 10 a 85 anos, com média de 22 anos (DP $\pm 12,47$ ) e predominância da faixa etária de 21 a 30 anos com $23(23 \%)$, seguida de 31 a 40 anos com 19 atendimentos (19\%), conforme consta na Tabela 1 abaixo.

Tabela 1 - Distribuição das vítimas de acidentes motociclísticos de acordo com o sexo e a faixa etária. Timon (MA), 2019.

\begin{tabular}{lcc}
\hline Faixa etária & $\mathrm{N}$ & $\%$ \\
\hline 0 a 10 & 1 & 1 \\
11 a 20 & 15 & 15 \\
21 a 30 & 23 & 23 \\
31 a 40 & 19 & 19 \\
41 a 50 & 14 & 14 \\
51 a 60 & 9 & 9 \\
$>60$ & 7 & 7 \\
Não Identificado & 12 & 12 \\
\hline Sexo & & \\
\hline Masculino & 69 & 69 \\
Feminino & 20 & 20 \\
Não Identificado & 11 & 11 \\
\hline Total & $\mathbf{1 0 0}$ & $\mathbf{1 0 0}$ \\
\hline Font: Abreu & &
\end{tabular}

Fonte: Abreu MSS, et. al., 2019.

A distribuição das vítimas por dia da semana e horários, mostra que prevalecem os acidentes ocorridos durante o fim de semana - sábado (34\%) e domingo (16\%). Às segundas-feiras também foram consideradas, pois se aproximam aos resultados do domingo (15\%). Quanto ao horário, predominou o turno da noite (39\%), seguidos da tarde (27\%) e da manhã (26\%). Conforme mostra a Tabela 2.

Tabela 2 - Distribuição das vítimas de acidente motociclístico de acordo com o dia da semana e o horário de ocorrência. Timon (MA), 2019.

\begin{tabular}{lcc}
\hline Dia da Semana & $\mathrm{N}$ & $\%$ \\
\hline Segunda-feira & 15 & 15 \\
Terça-feira & 8 & 8 \\
Quarta-feira & 5 & 5 \\
Quinta-feira & 9 & 9 \\
Sexta-feira & 13 & 13 \\
Sábado & 34 & 34 \\
Domingo & 16 & 16 \\
\hline Horário da Ocorrência & $\mathrm{N}$ & $\%$ \\
$07: 00$ às 11:59 & 26 & 26 \\
12:00 às 17:59 & 27 & 27 \\
18:00 às 23:59 & 39 & 39 \\
$00: 00$ às 6:59 & 8 & 8 \\
\hline Total & $\mathbf{1 0 0}$ & $\mathbf{1 0 0}$ \\
\hline
\end{tabular}

Fonte: Abreu MSS, et. al., 2019. 
Fica evidente um aumento progressivo do número de ocorrências no fim de semana em todos os horários, apesar de predominar entre 18:00h e 23:59h, se iniciando na sexta, atingindo pico no sábado e entrando em regressão no domingo. Estes resultados mostram que as pessoas envolvidas em acidentes estavam possivelmente de folga, em momento de divertimento, associado ao uso de bebida alcoólica, o que pode contribuir para a ocorrência dos acidentes, conforme Gráfico 1.

Gráfico 1 - Distribuição das Vítimas de Acidentes de Motocicleta de acordo com o dia da semana e o horário de Ocorrência. Timon (MA), 2019.

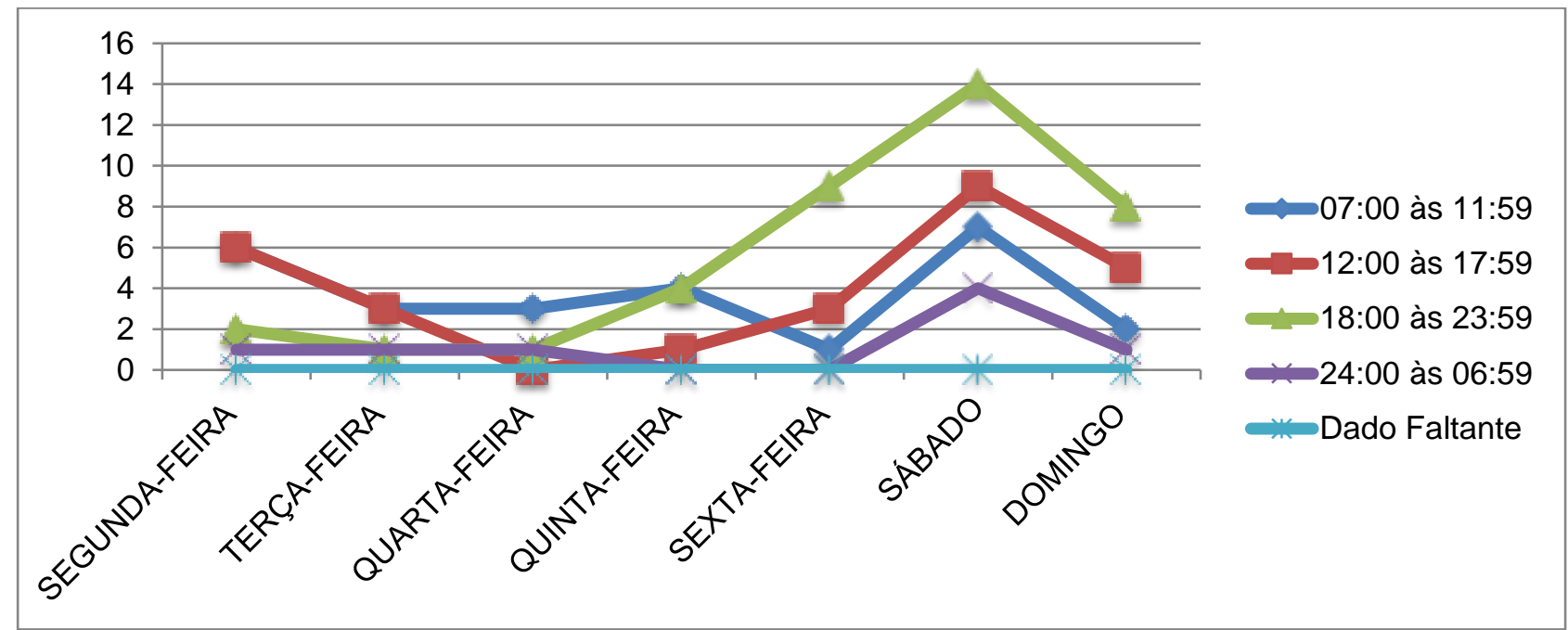

Fonte: Abreu MSS, et. al., 2019.

A preocupação do atendimento do SAMU ao receber uma ocorrência de acidentes é verificar a situação vital das vítimas. Diante disso, os dados indicativos de gravidade como o nível de consciência, pupilas e presença de sangramento mostram que a maioria das vítimas estava alerta (59\%) e sem alterações na avaliação das pupilas (71\%). Foi identificado presença de sangramento em $63 \%$, variando de mínimo (31\%), moderado $(20 \%)$ a intenso (12\%).

Levando em conta que alterações do nível de consciência e pupilar são indicativas de presença de traumatismo craniano, $36 \%$ das vítimas apresentavam alteração no nível de consciência, desde respondendo a comandos (20\%), apenas a dor (7\%) e não responsivos (9\%), assim como $13 \%$ tinham alterações nas pupilas.

Em relação à fala, em $63 \%$ dos casos estava normal, $16 \%$ ausente, $10 \%$ confusa e $11 \%$ das fichas de atendimento não contavam com essa informação. Vale destacar que, alterações no padrão de fala podem ser indicativas de traumatismo cranioencefálico e ingestão de bebida alcoólica.

Referente aos locais do corpo lesionados através dos acidentes de motocicleta, o presente estudo indica que são principalmente os membros inferiores (38\%), seguido da cabeça $(29 \%)$ - revelando a importância do uso de capacete. Vale ressaltar que em $26 \%$ das fichas não foram informadas as regiões lesionadas.

Durante o atendimento do SAMU, ao abordar a vítima, é necessário tomar algumas medidas durante 0 socorro. Neste estudo, em $59 \%$ das vítimas foi utilizada a prancha longa e em $49 \%$ o colar cervical. Em menores proporções foram utilizados curativos (27\%) e imobilização de extremidades (20\%). Não houve utilização de reanimação cardiopulmonar, prancha curta e nem foram identificados outros procedimentos.

Relacionado ao local das ocorrências, prevaleceu os acidentes ocorridos na zona urbana (85\%), ao passo que apenas $15 \%$ ocorreram na zona rural. Conforme observado, na zona urbana de Timon- MA, o local onde mais ocorreram acidentes foi a BR $316(18 \%)$ que passa dentro da cidade. O Parque Piauí também indica grande proporção nas taxas de acidentes relatados neste estudo (17\%), possivelmente por ser um bairro 
grande e movimentado. Em médias proporções, foram encontrados o Parque Alvorada e São Benedito, com 9\% dos casos. Dados constantes no Gráfico 2.

Gráfico 2 - Distribuição das vítimas de acidente motociclístico por bairros da zona urbana Timon (MA), 2019.

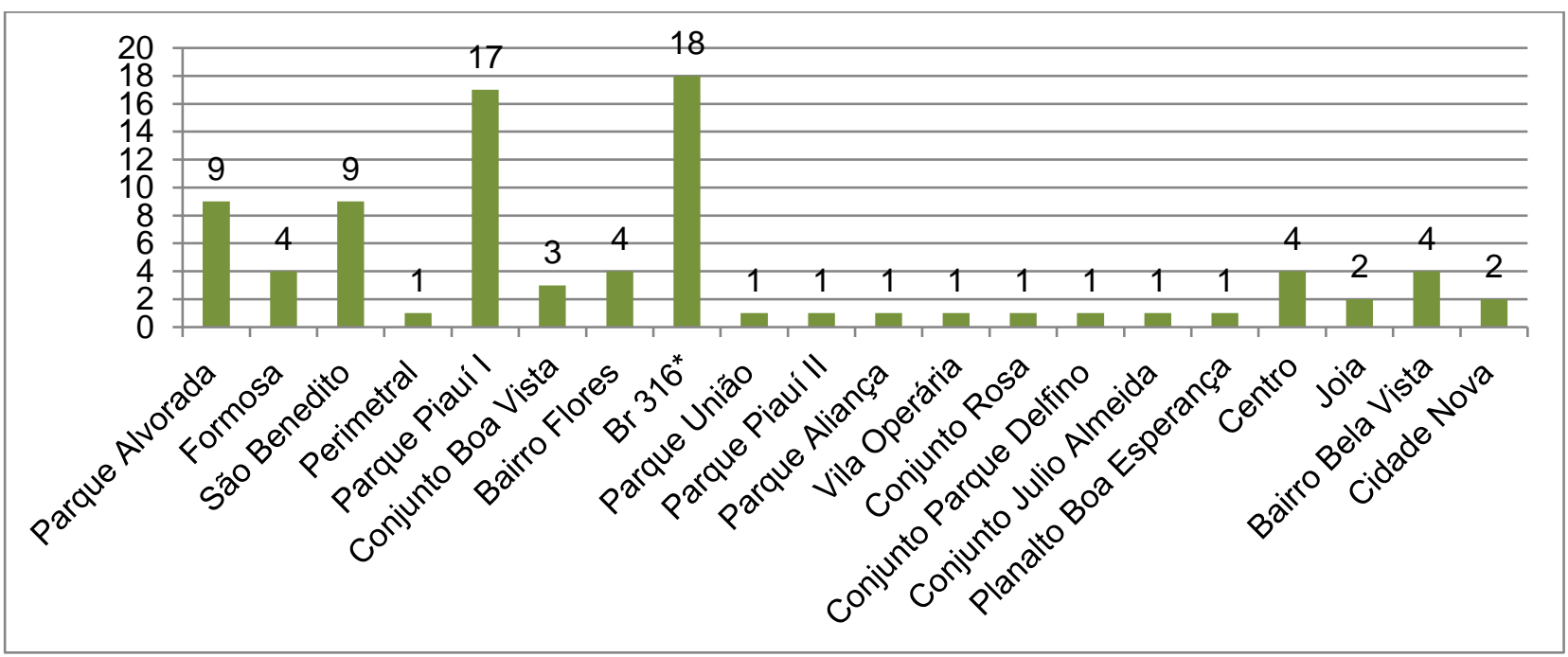

Fonte: Abreu MSS, et. al., 2019.

Infelizmente, os dados coletados neste estudo não permitiram analisar os fatores como presença de sinais de ingestão de bebida alcoólica e uso do capacete, pois a maioria dessas informações não estava presente nos impressos analisados. Conforme pode ser verificado, em $99 \%$ dos casos não houve informação em relação ao uso do capacete e em $76 \%$ sobre a ingestão de bebida alcoólica. Das fichas que estavam preenchidas o item sinais de ingestão de bebida alcoólica, em $23 \%$ não foi identificado sinais e apenas $1 \%$ foi verificada. Sobre a ocorrência de óbito, foi identificado em 3\% dos casos, sendo estes, antes do socorro (Tabela 03).

Tabela 03 - Distribuição das vítimas de acidentes motociclísticos segundo a utilização de capacete, suspeita de uso de álcool, unidade de atendimento e óbito. Timon (MA), 2019.

\begin{tabular}{llc}
\hline Uso de Capacete & $\mathrm{N}$ & $\%$ \\
\hline Sim & 0 & 0 \\
Não & 1 & 1 \\
Não Informado & 99 & 99 \\
\hline Suspeita de Ingestão de bebida alcóolica & $\mathrm{N}$ & $\%$ \\
Sim & 1 & 1 \\
Não & 23 & 23 \\
Não Informado & 76 & 76 \\
\hline Unidade de Atendimento & $\mathrm{N}$ & $\%$ \\
UPA Timon & 31 & 31 \\
Hospital Parque Alvorada & 6 & 6 \\
Hospital de Urgencia de Teresina & 28 & 28 \\
Outros & 2 & 2 \\
Não Identificado & 33 & 33 \\
\hline Òbito & $\mathrm{N}$ & $\%$ \\
Antes do socorro & 3 & 3 \\
Antes do transporte & 0 & 0 \\
Durante o Transporte & 0 & 0 \\
Não ocorreu óbito & 97 & 97 \\
\hline Total & 100 & 100 \\
\hline
\end{tabular}

Fonte: Abreu MSS, et. al., 2019. 
O presente estudo identificou, ainda, os locais para onde foram encaminhadas as vítimas dos acidentes, conforme as suas necessidades. Entre eles, prevalece a Unidade de Pronto Atendimento de Timon (31\%), que atende as pessoas desta cidade, seguido do Hospital de Urgência de Teresina (HUT) (28\%), sendo o hospital de referência para traumas de maior complexidade. No entanto, $33 \%$ dos casos não foram informados para quais hospitais foram levados, ou se houve esta necessidade.

\section{DISCUSSÃO}

O índice de acidentes motociclísticos é intenso levando em conta as ocorrências constantes atendidas pelo SAMU, pois a motocicleta é um veículo mais rápido e barato que proporciona menos segurança que o automóvel, levando muitas pessoas a óbito ou deixando lesões graves e permanentes quando envolvidas em acidentes de trânsito, visto que na maioria das vezes o condutor não se preocupa em utilizar o capacete de proteção (ALMEIDA GCM, et al., 2016).

Nesse sentido, o serviço de atendimento pré-hospitalar prestado pelo SAMU engloba todas as ações que ocorrem antes da chegada do paciente ao hospital e pode influenciar positivamente nas taxas de morbimortalidade durante as ocorrências dos acidentes. Desta forma, uma assistência qualificada é fundamental para que a taxa de sobrevida aumente, pois esta assistência ocorre no tempo crítico para a implementação do tratamento que modificará o prognóstico (FRANCO MS, et al., 2015).

Um estudo realizado em Teresina, também apontou a prevalência de vítimas do sexo masculino - mais de 70\% - com faixa etária de 24 a 29 anos (47,5\%), seguida da faixa etária de 18 e 23 anos (23,7\%) (CAVALCANTE AC, et al., 2015). Trabalhos desenvolvidos por Silva ACM, et al. (2017) identificaram que, no período compreendido entre 2000 a 2010, o crescimento do índice de acidentes motociclísticos aumentou $244 \%$, sendo a maioria das vítimas com faixa etária entre 19 e 29 anos e do sexo masculino.

Observando estudo de Mendonça MFS, et al. (2017), no período delimitado foram atendidas 1.225 vítimas de acidente de trânsito pelo SAMU na cidade do Recife (PE), o valor corresponde a 45,4\% do total de atendimentos que foram realizados pelo serviço $(n=2.698)$, levando em consideração todas as causas de atendimento. As vítimas foram na sua maioria do sexo masculino (razão de 3,6 homens para cada mulher). A faixa etária predominante foi a de 20 a 29 anos de idade, e a de menor frequência, de 0 a 9 anos.

Uma possível explicação para a predominância do sexo masculino é a de que os homens circulam com maior frequência no perímetro urbano, além do comportamento mais agressivo, consumo de álcool, velocidade excessiva, manobras imprudentes, tornando-os mais expostos a ocorrência de acidentes de trânsito. Em relação à predominância da população mais jovem, mostra a vulnerabilidade desta parcela da população, que se encontra em uma idade economicamente ativa, o que pode comprometer a renda familiar e diminuir a força de trabalho, pois as vítimas na maioria das vezes têm que se afastar temporariamente, em alguns casos definitivamente das atividades laborais por conta das lesões decorrentes do acidente. (FRANCO MS, et al., 2015). Diferente dos estudos desta pesquisa, Muniz JS, et al. (2016), detectaram em estudo realizado na Região Administrativa Sul do Distrito Federal, que a maioria dos envolvidos em acidentes motociclísticos também são homens, sendo $78 \%$ com média de idade de 31 anos e que as ocorrências foram na sua maioria no domingo (21,55\%) e no horário correspondente entre as 12h00min e 17h59min (39,65\%).

No estudo de IbiapinoMK (2017), as ocorrências concentraram-se nos finais de semana, principalmente aos domingos $(19,9 \%)$, seguido dos sábados $(17,9 \%)$, com predomínio de atendimentos noturnos entre $18 \mathrm{~h} 01 \mathrm{~min}$ e $00 \mathrm{~h} 00 \mathrm{~min}$ horas $(52,0 \%)$, seguido pelo período entre $12 \mathrm{~h} 01 \mathrm{~min}$ e $18 \mathrm{~h} 00 \mathrm{~min}(36,0 \%)$. No que diz respeito ao horário dos atendimentos, verificou-se que os deste último estudo foram aproximados aos identificados nesta pesquisa.

Em pesquisa desenvolvida por Barbosa MK (2014), identificou que aproximadamente $43,0 \%$ das vítimas atendidas pelo SAMU apresentavam lesões na cabeça, seguido dos membros inferiores $(38,6 \%)$ e dos membros superiores (25,6\%). De acordo com os pesquisadores, uma possível explicação para as lesões serem predominantemente na cabeça pode estar associada ao fato que os motociclistas na cidade onde realizaram a pesquisa não utilizam capacete, prática bastante comum em cidades do interior. Deste modo, as 
lesões nesta pesquisa se diferenciam diretamente relacionando à exposição corporal a qual o veículo as predispõe. Os acidentes ocorridos na Zona Rural podem ser ocasionados por diversos fatores, como quedas, colisões com carros, motos, animais ou objetos fixos na estrada. Sabe-se que a maioria dos acidentes tem causas específicas que os desenvolvem e muitas delas é a ingestão de bebidas alcoólicas, já que, quando um condutor manuseia um veículo nestas condições, aumenta o risco de acidentes. Além disso, a ausência do uso de capacete aumenta os riscos de óbitos e lesões cranioencefálicas (SILVA ACM, et al., 2017).

Já no trabalho realizado por Cavalcante AC, et al. (2015), identificou-se que a maioria das vítimas estavam alertas $(64,5 \%)$, com pupilas iguais $(81,5 \%)$, fala normal $(69,4 \%)$ e pulso forte $(66,9 \%)$. Entretanto, nesse estudo os atendimentos eram de baixa complexidade, sendo caracterizado pela maioria ser regulado para atendimento de suporte básico, enquanto nesta pesquisa foram avaliados os atendimentos de suporte avançado. Ao se investigar sobre os tipos de lesões encontradas, verificou-se que a maior parte foi escoriação $(65 \%)$, seguido de ferimentos corte-contuso $(22 \%)$, contusão (18\%) e fratura aberta $(11 \%)$.

O padrão de lesão e sua gravidade são influenciados pela aceleração, direção da força envolvida no acidente, posição da vítima no veículo, idade, uso de equipamentos de segurança, e ainda, tipo e tamanho dos veículos envolvidos. O atendimento prestado pelas unidades de suporte do SAMU mostra-se indispensável nos acidentes de trânsito, visto que um atendimento rápido e especializado pode amenizar as sequelas e a incidência de óbitos (CAVALCANTE AC, et al., 2015).

Sabe-se que a maioria dos acidentes tem causas específicas que os desenvolvem e muitas delas é a ingestão de bebidas alcóolicas, já que, quando um condutor manuseia um veículo nestas condições, aumenta o risco de acidentes. Além disso, a ausência do uso de capacete aumenta os riscos de óbitos e lesões cranioencefálicas. $\mathrm{O}$ autor destaca em suas considerações a prevalência de acidentes envolvendo moto taxistas. Em seu estudo, 63,6\% dos acidentes envolvem estes trabalhadores e a maioria estava com o uso do capacete, o que reduziu a taxa de óbitos nestes acidentes (ALMEIDA PMV, et al., 2016).

Dos fatores de risco que podem causar acidentes, em estudo de Nascimento NWS e Alves SM (2013), a maioria das vítimas (81\%) não possuíam Carteira Nacional de Habilitação, $86 \%$ não faziam o uso do capacete, $52 \%$ ingeriram algum tipo de bebida alcoólica, $43 \%$ já tinham sofrido algum tipo de acidente anterior e os finais de semana são os dias mais prevalentes dos eventos (62\%). Porcentagens menores, como animais (33\%) e objetos fixos (33\%) foram considerados também como causadores da colisão.

De acordo com Barbosa MK (2014), o predomínio das quedas de motocicleta pode estar relacionado à imprudência, no que se refere ao excesso de velocidade e ao consumo de bebidas alcoólicas. Dantas RAN, et al. (2018), confirmam estes dados, em seu estudo verificou- se que $61(48,8 \%)$ dos entrevistados tiveram seus membros superiores e/ou inferiores (MMSS/II) afetados e/ou cintura pélvica, seguidos por $38(30,4 \%)$ que sofreram politrauma. Diante disso, o cuidado às vítimas deve ser iniciado no atendimento pré-hospitalar. O cuidado desses pacientes apresenta algumas peculiaridades que requerem de toda a equipe de saúde, atuação específica, bem como o uso de equipamentos, visando diminuir o risco de sequelas.

A pesquisa desenvolvida por Barbosa MK (2014), identificou que aproximadamente $43,0 \%$ das vítimas atendidas pelo SAMU apresentavam lesões na cabeça, seguido dos membros inferiores $(38,6 \%)$ e dos membros superiores (25,6\%). De acordo com os pesquisadores, uma possível explicação para as lesões serem predominantemente na cabeça pode estar associada ao fato que os motociclistas na cidade onde realizaram a pesquisa não utilizam capacete, prática bastante comum em cidades do interior. Deste modo, as lesões nesta pesquisa se diferenciam diretamente relacionando à exposição corporal a qual o veículo as predispõe.

Almeida GCM, et al. (2016) destacam em suas considerações a prevalência de acidentes envolvendo moto taxistas. Em seu estudo, 63,6\% dos acidentes envolvem estes trabalhadores e a maioria estava com o uso do capacete, o que reduziu a taxa de óbitos nestes acidentes. O índice de acidentes motociclísticos é intenso levando em conta as ocorrências constantes atendidas pelo SAMU. A motocicleta é um veículo que proporciona menos segurança que o automóvel, levando muitas pessoas a óbito ou deixa lesões graves e permanentes quando envolvidas. 
Na concepção de Barbosa MK (2014), o predomínio das quedas de motocicleta pode estar relacionado à imprudência, no que se refere ao excesso de velocidade e ao consumo de bebidas alcoólicas. Em um estudo realizado em Teresina, consta que $75,7 \%$ das vítimas atendidas no Hospital de Urgência de Teresina (HUT) são de acidentes de trânsito, sendo que muitas dessas vítimas vêm da cidade vizinha de Timon (MA). O hospital, por sua vez informou aos pesquisadores que os atendimentos de acidentes são na maioria no período noturno, o que comprova as estatísticas dos dados coletados nesta pesquisa (CAVALCANTE AC, et al., 2015).

\section{CONCLUSÃO}

Constatou-se que o índice de acidentes de motocicletas atendido pelas Unidades de Suporte Avançado de Vida do SAMU de Timon (MA) é elevado, com predominância do sexo masculino, em idade jovem considerada economicamente produtiva, nos fins de semana, no perímetro urbano e com ocorrência de lesões principalmente em membros inferiores e cabeça. Vale destacar que, uma das dificuldades na realização deste estudo foram informações incompletas nas fichas de atendimento do SAMU, pois os profissionais deixaram de preencher o impresso de maneira adequada, principalmente no que diz respeito a sinais de ingestão de bebida alcoólica e uso do capacete. Isso prejudicou os resultados do estudo, não permitindo a realização de relações estatísticas dos dados encontrados.

\section{REFERÊNCIAS}

1. ALMEIDA GCM, et. al. Prevalência e fatores associados a acidentes de trânsito com mototaxistas. Rev Bras Enf. 2016; 13(1): 382-388.

2. ALMEIDA PMV, et. al. Análise dos atendimentos do SAMU 192: Componente móvel da rede de atenção às urgências e emergências. Esc Anna Nery 2016; 20(2): 289-295.

3. BRASIL. Ministério da Saúde. VIVA: Vigilância de Violências e Acidentes. Departamento de Vigilância de Doenças e Agravos não Transmissíveis e Promoção da Saúde. Brasília, 2017.

4. BRASIL. Ministério da Saúde. Protocolos de intervenção para o SAMU 192: Serviços de Atendimento Móvel de Urgência. Brasília, 2016.

5. BARBOSA MQ. Acidente motociclístico: caracterização das vítimas socorridas pelo Serviço de Atendimento Móvel de Urgência (SAMU). Rev Bras de Ciências da Saúde. 2014; 18(1): 03-10.

6. CAVALCANTE AC, et. al. Perfil de acidentes de tráfico assistida em serviço pré-hospitalar móvel. Rev Baiana de Enf. 2015; 29(2): 135-145.

7. DANTAS RAN, et al. Vítimas de acidentes de trânsito atendidas por serviço pré-hospitalar móvel de urgência. Revista de Enfermagem do Centro-Oeste Mineiro. 2018; 8: e2549.

8. FRANCO MS, et al. Caracterização de pacientes vítimas de acidentes de trânsito admitidos em hospital regional da Paraíba. R Interd. 2015; 8(2): 123-29.

9. HANAUER MC, et al. Caracterização dos atendimentos realizados pelo SAMU. Rev enferm UFPE on line., Recife. 2018; 12 (12): 3476-83.

10. IBIAPINO MK. Serviço de atendimento móvel de urgência: epidemiologia do trauma no atendimento pré-hospitalar. Rev da Facul de Ciências Médicas de Sorocaba. 2017; 19(1): 72-5.

11. LEFUNDES DAA, et al. Caracterização das ocorrências do serviço de atendimento móvel de urgência. Rev Baiana de Enfermagem. 2016; 30(3): 1-10.

12. MENDONÇA MFS, et al. Análise espacial dos acidentes de trânsito urbano atendidos pelo Serviço de Atendimento Móvel de Urgência: um recorte no espaço e no tempo. Rev bras epidemiol. 2017; 20(4): 727-741.

13. MUNIZ JS, et al. Incidência de acidentes de motocicleta nas cidades-satélites do Recanto das Emas, Samambaia e Riacho Fundo II no Distrito Federal. Primeiro Simpósio de TCC e Seminário de IC. 2016: 984-989.

14. NASCIMENTO NWS, ALVES SM. Perfil dos motociclistas vítimas de acidente de trânsito atendidos no serviço de urgência municipal de Alto Longá. Rev Saúde e Desenv. 2013; 04(2).

15. SILVA MGP, et al. Lesões craniofaciais decorrentes de acidentes por motocicleta: uma revisão integrativa. Revista CEFAC. 2015; 17(1): 1689-97.

16. SILVA ACM, et al. Acidentes de trânsito envolvendo motociclistas na zona rural de Porteirinha, Minas Gerais. Rev Dig Buenos Aires. 2017; 232(22). 